\title{
“GESTÃo de UMA HERANÇA”: A HISTÓRIA GENÉTICA DOS OBJETOS TÉCNICOS NA FILOSOFIA DE Gilbert Simondon
}

\author{
Ericson S. Falabretti ${ }^{1}$ \\ Jelson R. de Oliveiral
}

Resumo: Pretende-se, com este artigo, analisar o conceito de história genética no pensamento do filósofo francês Gilbert Simondon. Para isso, faz-se necessário analisar a proposta de uma filosofia a qual pretende romper com as barreiras que separam técnica e cultura, a fim de, a partir daí, examinar o modo próprio de existência dos objetos técnicos. Nessa perspectiva, analisa-se a tecnicidade da técnica, utilizando-se do conceito de invenção, com vistas a formular uma história genética da técnica que recolhe, ao mesmo tempo, elementos subjetivos (psicológicos) e objetivos (tecnológicos), segundo o método transdutivo. Um projeto que, ao final, se apresenta como "gestâo de uma herança", segundo a expressão de Merleau-Ponty.

Palavras-Chave: Simondon. Técnica. Genética. Invenção. Evolução.

\section{INTRODUÇÃO: DE COMO OS OBJETOS TÉCNICOS SÃO [DEVEM SER] OBJETOS FILOSÓFICOS}

A análise da realidade própria dos objetos técnicos é um tema expoente da obra do filósofo e engenheiro francês Gilbert Simondon. Sua filosofia, vertida numa linguagem conceitual rara, se apresenta como uma ontologia dos objetos técnicos que ocupam, permeiam e medeiam a relação do homem com o mundo. Nesse sentido, a reflexão de Simondon recolhe e prolonga um desafio fenomenológico através de sua pergunta sobre a realidade genética, ou seja, o aparecimento dos seres técnicos. Formulada nesses termos, tal pergunta trata a gênese na perspectiva de um "princípio de individuação anterior à indi-

\footnotetext{
${ }_{1}^{1}$ Professor do Programa de Pós-Graduação em Filosofia da PUC-PR, Curitiba, PR - Brasil. E-mails: ericson.falabretti@pucpr.br; jelson.oliveira@pucpr.br

O presente artigo é resultado de pesquisa apoiada pela Capes e CNPq.

http://dx.doi.org/10.1590/0101-3173.2018.v41n2.10.p177
}

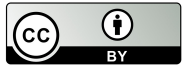

This is an open-access article distributed under the terms of the Creative Commons Attribution License. 
viduação ela mesma” como uma "categoria ontológica” (BEISTEGUI, 2005, p. 143) que quer reconhecer a emergência da sua manifestação no seu devir próprio. Uma história genética da técnica, portanto, caracteriza-se como uma reflexão sobre o horizonte pré-individual - a forma simondoniana de conceber uma Lebenswelt da técnica - do qual emergem os seres técnicos. Trata-se de reconhecer "que o indivíduo não é todo ser, mas somente uma de suas fases, e na realidade sua última fase." (BEISTEGUI, 2005, p. 143). É nesse horizonte que se situa a pergunta sobre a máquina e os demais objetos técnicos: como ontologia, ela se apresenta como uma análise da emergência de tais objetos um pensamento que, no limite, deve ser formulado a partir de uma interrogação a respeito da sua invenção.

Ora, um tal interesse pela realidade dos objetos técnicos parece náo ter sido comum na tradição filosófica e, mais, ele vem sendo contraposto àquilo que poderíamos chamar de interesse cultural. $\mathrm{Na}$ introdução da sua obra de 1958, intitulada Du mode d'existence des objets techniques ${ }^{2}$, o autor reclama de uma cultura que recusa o pensamento sobre os objetos técnicos em nome de uma pretensa "defesa do homem", como se tais objetos "náo contivessem nenhuma realidade humana." (MEOT, 9). Obviamente, a posição do filósofo francês é bem outra: para ele, a pergunta sobre o modo próprio de ser dos objetos técnicos é uma das perguntas possíveis a respeito do homem e de sua forma de estar no mundo, embora seja, antes disso, uma pergunta sobre a dignidade própria e autorreferenciada dos objetos técnicos: o estudo da técnica concerne à natureza propriamente técnica dos objetos técnicos; nesse sentido, deve-se reconhecer que os objetos técnicos revelam uma ordem de realidade própria. Por isso, trata-se, para ele, de romper a barreira que costumeiramente separa a cultura e a técnica, uma bifurcação que seria ao mesmo tempo falsa e sem fundamento, mas que, em nome de um "humanismo fácil”, acaba por mascarar "uma realidade rica em esforços humanos e em forças naturais que constituem o mundo dos objetos técnicos, mediadores entre a natureza e o homem." (MEOT, 9).

Simondon chega a afirmar que há mesmo uma espécie grave de "xenofobia" contra esse mundo desconhecido dos objetos técnicos ${ }^{3}$, algo que se sustenta sobre o misoneísmo de uma cultura que não aceita o horizonte técnico das máquinas. Uma cultura tecnofóbica por excelência, portanto. Se a "máqui-

\footnotetext{
2 Doravante MEOT.

${ }^{3} \mathrm{O}$ que não aconteceria, por sua vez, com os objetos estéticos e mesmo com os objetos sagrados, muito mais integrados culturalmente.
} 
na é o estrangeiro", então a cultura precisa, como acontece com todo forasteiro, integrá-la e descobri-la como parte da realidade humana. Para Simondon,

\begin{abstract}
a mais forte causa de alienação no mundo contemporâneo reside no desconhecimento da máquina, que não é uma alienação causada pela máquina, mas pelo desconhecimento de sua natureza e de sua essência, por sua ausência do mundo das significaçóes, e por sua omissão no quadro de valores e de conceitos que fazem parte da cultura. (MEOT, 10).
\end{abstract}

Está justificada assim a necessidade filosófica de analisar o modo de existência dos objetos técnicos: trata-se de romper as barreiras que abordam tais objetos como sem estrutura de significação e unicamente a partir de seu poder de uso, ou seja, de sua utilidade funcional, que seria, para o filósofo, uma visão pobre, porque leva em conta apenas a realidade extrínseca e não aquilo que é a existência mesma de tais objetos.

Essa, contudo, não é a única justificativa de uma filosofia da técnica nos moldes propostos por Simondon. Tal recusa da realidade íntima dos objetos técnicos teria despertado, paradoxalmente, naqueles que valorizam o seu conteúdo cultural, certos exageros na forma de um "tecnicismo intemperante" muito próximo de uma "idolatria da máquina”, a qual resulta numa "aspiração tecnocrática ao poder incondicional” (MEOT, 10), típica de uma atitude tecnofílica exagerada. Nesse caso, uma filosofia que leve em conta os objetos em sua realidade própria também pode contribuir para dirimir esse tipo de atitude extrema. Só um pensamento sobre os dispositivos técnicos poderia evitar que o homem fosse dominado pela supremacia da máquina e pelo encantamento suscitado por ela, diante do seu mau uso. Só assim o homem poderia deixar de abdicar de si mesmo, por meio de uma intervençáo inautêntica e mal-intencionada da máquina, como pretensamente ocorreria com aquele "duplo do homem que é o robô", a máquina humanizada, o homem maquinizado algo que Simondon afirma não existir, sendo apenas um produto imaginativo, fictício, fruto da "arte da ilusão" que acaba por influenciar o modo como a cultura se relaciona com a máquina. A interdição do discurso em torno dos objetos técnicos, portanto, conduziria tanto à utopia da sua perfeição quanto à tecnofobia. Porque não entende a máquina e não tematiza os objetos técnicos, o homem cria ilusôes, entre as quais estaria a crença no domínio total das máquinas sobre a realidade humana e a ideia de que elas ameaçam o homem, como se tivessem uma existência autônoma capaz de usar todo tipo de expedientes contra o homem. Eis a visão da cultura da primeira metade do século 
XX que Simondon pretende investigar e contra a qual pensa, a partir da análise de "duas atitudes contraditórias" em relação aos objetos técnicos: em um extremo, eles são compreendidos como um conjunto de matéria destituído de qualquer significação cultural; no outro, são seres animados por intenções hostis contra o homem. Sua insistência estaria em mostrar que há mais interaçôes nesse âmbito do que geralmente se imagina: "as necessidades se moldam sobre o objeto técnico industrial, que adquire assim o poder de modelar uma civilização." (MEOT, 28).

Na sua tentativa de demonstrar que a técnica e a cultura são dois âmbitos de realidade que se encontram coligados, Simondon afirma a existência de um conjunto, de uma rede de trocas que articula máquina, homem e mundo. Para explicar essa posição, o autor lança mão de uma metáfora contundente: o homem é o maestro dessa grande orquestra de máquinas com as quais ele partilha o mundo e, mesmo que não tenha em mãos cada um dos objetos que produzem o som, sendo apenas a "forma movente e atual" que mobiliza o grupo, ele articula e relaciona os vários instrumentos. Por isso, no campo técnico, "o homem tem a função de ser o coordenador e o inventor permanente das máquinas que estão em torno dele.” (MEOT, 13). A obviedade da conclusão salta à vista: não há máquina, se não houver homem, o que significa que nela, na máquina, reside uma realidade humana na forma de arcabouços que funcionam automaticamente. Na base dessa relação está a abertura da máquina ao mundo, na forma de uma sensibilidade para a informação, que se revela na margem de indeterminação que lhe é própria e que é coordenada pelo homem.

\section{A TECNICIDADE DA TÉCNICA}

A história da técnica deve ser contada através de quatro fases que são compreendidas de forma sucessiva e cumulativa, de sorte a reconhecer, em cada época, características e hábitos da época precedente: a fase artesanal, marcada pela transmissão de conhecimentos técnicos de uma geração a outra, por meio de um modo de trabalho que mantém relação direta com os ritmos naturais; a fase enciclopédica, caracterizada pela difusão de um saber racional; a fase contemporânea das revoluçôes industriais, identificada pela defasagem entre o ritmo humano e o ritmo das máquinas; e, por último, a fase cibernética, designada pela otimização de energias e pela alta capacidade transmissáo de informaçáo. Para o filósofo, esta última fase guarda uma possibilidade de 
anulação da defasagem provocada na terceira fase, através de um reconhecimento da complementaridade entre o homem e os objetos técnicos. Por isso, em seu projeto filosófico, Simondon afirma a importância de tratar os objetos técnicos como prolongamento da atividade humana e a técnica em geral como extensão da cultura, embora, para isso, pressuponha que a história da técnica se constitui em uma exposição de invençóes segundo a ordem de apariçóes, ou seja, do ponto de vista fenomenológico, podemos falar de uma história da técnica como se falássemos de uma história natural, algo que, afinal, lhe daria uma "história" própria: "A gênese do objeto técnico faz parte de seu ser" e o "objeto técnico é o que não é anterior ao seu tornar-se", uma "unidade de tornar-se." (SIMONDON, 2005, p. 20).

Na primeira e segunda parte de Du mode d'existence des objets techniques, Simondon realiza uma descrição e uma interpretação ${ }^{4}$ dessa história, partindo de uma convicção: é preciso fundar uma história da técnica sobre condiçôes próprias e não extrínsecas, o que significa contar o desenvolvimento da técnica a partir da técnica mesma ou, em outras palavras, a partir daquilo que ele chama de "essência do objeto técnico"; a partir da tecnicidade e não dos seus efeitos. É aí, na tecnicidade do objeto, portanto, que está o dado principal da técnica que se abre para a filosofia como "processo de concretização e de sobredeterminação funcional que lhe dá sua consistência na forma de uma evolução, provando que ele [o objeto técnico] não será considerado como um puro utensílio.” (MEOT, 17). Para Simondon, a tecnicidade, por isso, é "uma das formas básicas em que o homem foi estruturando a sua relação humana com a Natureza” (CUPANI, 2013, p. 71) e por ela seria possível recontar a gênese dos objetos técnicos, como um conjunto de condicionamentos e incitaçóes à ação que marcam o ato inventivo. Tal ato seria caracterizado sempre pela criação de um indivíduo, em função da imaginação técnica diante de um desafio apresentado pelo mundo, algo que é definido por Simondon como "uma sensibilidade particular para a tecnicidade dos elementos" e que, no limite, nunca ocorre ex nibilo, com base na capacidade de dar forma à matéria, mas por elementos já técnicos "para os quais se descobre um ser individual suscetível de lhes ser incorporado." (MEOT, 92). Tais objetos seriam testemunhas desse ato e, portanto, deveriam ser integrados à cultura, como já vimos acima, por traduzirem expectativas e circunstâncias humanas, sociais e culturais.

\footnotetext{
${ }^{4}$ Chabot (2003, p. 241) caracteriza a filosofia de Simondon como uma filosofia da "compreensão", ou seja, ela não estaria necessariamente orientada para ação no campo ético e político.
} 
Para essa tarefa, seria necessário analisar os três níveis do objeto técnico: do elemento (associado ao entusiasmo com o progresso típico do século XVIII), do indivíduo (ou seja, das máquinas propriamente ditas, as quais se incluem na era da termodinâmica [século XIX] de forma profética e cataclísmica) e do conjunto (a era da informação do século XX, em que a técnica é vista em suas regras de estabilidade, dado o aumento de informação que ela traz, opondo-se à degradação do nível anterior). Tal compreensão é necessária porque, assegura Simondon, uma vez "o objeto técnico estando definido por sua gênese, é possível entâo estudar as relaçôes entre os objetos técnicos e as outras realidades, em particular o homem no estado adulto ou infantil." (MEOT, 17). É justamente no nível do conjunto que a máquina passa a ser uma aliada do homem e, mais ainda, é nesse nível que "a realidade técnica, tornada reguladora, poderá se integrar à cultura, reguladora por essência.” (MEOT, 18).

Para tanto, seria preciso [1] rever o caráter evolutivo do objeto técnico e [2] o seu fundamento ontológico e fenomenológico, o que significa, mais especificamente, atentar para a dimensão evolutiva genética que revela o sentido temporal de sua evolução, não de maneira classificatória ou meramente operacional, mas genética. Por isso, a tarefa filosófica deveria dar conta de dois expedientes inseparáveis: primeiro, reconhecer e analisar a existência própria dos objetos técnicos e, segundo, perguntar sobre essa existência, a partir do seu modo de temporalidade: "É preciso notar a nitidez da afirmação do caráter temporal do objeto técnico em sua essência mesma, que aparece justamente na consideração de sua unidade e de sua individualidade." (CHATEAU, 2005, p. 37). Isso porque, conforme Simondon,

a unidade do objeto técnico, sua individualidade, sua especificidade, são os caracteres de consistência e de convergência de sua gênese. A gênese do objeto técnico faz parte de seu ser. O objeto técnico é algo que não é anterior ao seu devir, mas presente em cada etapa deste devir; o objeto técnico é uma unidade de devir. (MEOT, 22).

Trata-se de trazer à tona o caráter evolutivo da técnica, reconhecendo-a na sua temporalidade própria, ou seja, destacando a sua gênese - embora isso não seja tão fácil, já que, no caso dos objetos técnicos em sua individualidade, eles se modificam no curso de sua própria gênese (MEOT, 21) e não se apresentam a não ser como sempre novas fases dessa história genética que eles, 
a um tempo, são e provocam. Nesse sentido, a história genética dos objetos associa-se à tarefa de contar a história do próprio homem.

\section{A INVENÇÃo do OBJETo TÉCNICO E A "GESTÃo de UMA HERANÇA”}

No seu projeto filosófico, Simondon dá destaque para a questão da invenção, um tema que aparece de forma constante nas suas obras publicadas, bem como na maior parte de seus cursos e conferências. O tema é tratado, principalmente, do ponto de vista do domínio técnico (o que não exclui preocupaçóes do âmbito artístico, religioso ou mesmo filosófico), levando em conta sua importância para a análise da história genética da técnica, no sentido em que, pelo ato inventivo, a realidade técnica é produzida: "As realizações técnicas aparecem por invenção", afirma Simondon, na primeira frase de um texto intitulado L'invention dans les techniques, conferência realizada num colóquio sobre Mecanologia ${ }^{5}$, no ano de 1971. A invenção serve, portanto, como conceito-chave para a caracterização do modo de existência próprio dos objetos técnicos, o que significa que ela traduz o esforço filosófico de descrição de uma ordem de realidade que está guardada no âmago de todos os objetos técnicos e que caberia à filosofia decifrar, decodificar, compreender. A invenção seria um conceito capaz de se integrar tanto a uma teoria psicológica da atividade humana quanto a uma teoria tecnológica da realidade inventada. Ao integrar essas duas realidades, Simondon utiliza o conceito no âmbito de sua teoria genética, para a qual, conforme Chateau (2005, p. 15), ainda seria preciso encontrar alguma unidade interpretativa.

A análise do caráter evolutivo genético é, assim, indispensável para a compreensão da realidade técnica e, para uma tal apreciação, seria preciso recorrer ao "sentido temporal de sua evolução" (MEOT, 22) que começa a ser pensado justamente com o conceito de invenção, pois é ele que doa a esses objetos o seu caráter essencialmente genético. É por esse ato inventivo que se desenvolvem todos os demais processos de "saturação progressiva" (MEOT, 32), os quais nascem das sempre novas incompatibilidades que exigem atualização, reparação, rearranjos e outros processos marcantes do devir, resultados da atividade interna do próprio sistema. ${ }^{6}$ Seria preciso, portanto, perguntar se

\footnotetext{
5 Sobre esse colóquio, ver Domingues (2015). A mecanologia, como estudo da realidade própria das máquinas, não só é preconizada por Simondon, como serviria de epíteto ao projeto filosófico a $D u$ mode d'existence des objets techniques.

${ }^{6}$ Todos esses processos técnicos são descritos de forma exaustiva por Simondon, contando com um vocabulário próprio de sua experiência como engenheiro.
} 
a invenção é um evento subjetivo, ou seja, deve ser investigada desde a perspectiva de seu inventor, ou, ao contrário, é objetivo, isto é, deve ser estudada do ponto de vista do objeto inventado. A resposta de Simondon tenta integrar as duas posiçôes, demostrando que a história objetiva da invenção não pode ignorar os dados psicológicos e subjetivos de seus inventores. Desse modo, o filósofo francês continua cumprindo seu projeto de integração entre a realidade técnica e a realidade cultural: ao falar de invenção, ele se refere a uma experiência que se realiza e procede "de um ser vivo dotado de inteligência e de capacidade de antecipação, dissimulação" (MEOT, 23), atividades estas que são tidas, pelo autor, como exercícios mentais geradores da realidade técnica, porque provocadas pelos problemas surgidos no próprio mundo. Nesse caso, todo objeto técnico mantém uma coerência e uma relação íntima, enquanto obra, com seu inventor, na forma de uma tentativa de solução de um problema real: a invenção é uma atividade intelectual de resolução de problemas e, por isso, serve de ligação entre a criatividade (própria de um ou vários sujeitos criadores em ato cooperativo) e a funcionalidade própria do objeto (como ser criado em resposta a problemas concretos). A psicologia da invenção, assim, seria uma psicologia reflexiva e reconstrutiva, e até mesmo arqueológica, na medida em que pretende reconstituir os traços centrais do evento subjetivo que está contido na realidade técnica. A questão, é que, nesse modo, uma tal psicologia precisa ser também uma espécie de tecnologia, pois é no objeto técnico que ela precisa descobrir o aspecto mental da invenção. É nessa mesma medida que uma tal psicologia se caracteriza igualmente como uma fenomenologia do modo próprio de existência dos objetos técnicos, um estudo sobre o seu surgimento e sua história: "Somente um conhecimento tecnológico do objeto inventado tornaria possível um conhecimento adequado de sua invenção." (CHATEAU, 2005, p. 19). No conceito de invenção estão reunidos (até mesmo diluídos) tanto sujeito quanto o objeto, algo que, no limite, faz do método de Simondon um método transdutivo ${ }^{7}$, quer dizer, um caminho entre dados singulares individuais e suas relações entre si.

\footnotetext{
$7 \mathrm{Na}$ sua obra dedicada ao seu antigo mestre Merleau-Ponty, Simondon define a transduçẫo nas seguintes palavras: "A operação transdutiva é uma individuação em progresso." (SIMONDON, 1989, p. 24). Trata-se, assim, de um método que opera segundo a lógica da propagação de uma informação no interior de um determinado domínio, algo que é aplicado tanto ao ato de um cristal que se estende em todas as direçóes, a partir de um germe inicial, até à maturação orgânica, à atividade do pensamento e, claro, ao âmbito da técnica. O conceito se diferencia do uso por parte da física, da biologia e das neurociências, para destacar o pluralismo que engendra todo processo de individuaçáo e pretende demonstrar que toda realidade é ordenada de forma transdutiva e náo meramente classificatória. Ocorre que, segundo o autor, a própria filosofia deveria romper com sua vocação monolítica, sedimentada e fragmentada, para intuir as relaçôes que formam a vasta realidade, reconhecendo as
} 
Além desse lado subjetivo e psicológico da análise de Simondon, há também a perspectiva objetiva, aquela que se situa do ponto de vista tecnológico e que parte de uma dificuldade inicial: a análise fenomenológica e ontológica dos objetos técnicos deve levar em conta que tais objetos não são nem seres vivos, nem simplesmente matéria inerte, nem meros artefatos e nem somente resultado de uma aplicação do conhecimento científico. Além disso, é necessário reconhecer que um objeto técnico não encontra sua existência simplesmente no fato de ser algo utilizável, mas, sobretudo, em suas estruturas e mecanismos físicos próprios. Conforme Simondon, "a gênese do objeto técnico faz parte de seu ser.” (MEOT, 20). Com seu método transdutivo, o autor faz notar que a característica própria de um objeto técnico é sua inserção numa linha evolutiva, a compreensão desse objeto como momento ou estado que representa a unidade deste ser individual com seu precedente e o subsequente. Trata-se de questionar o lugar de cada objeto técnico, no processo de continuidade evolutiva ao qual ele pertence. Nem funcionamento, nem estrutura, nem utilidade seriam suficientes para caracterizar a existência própria de tais objetos. É preciso descobrir a sua descendência no curso genético que garante certa identidade em meio às mudanças próprias da evolução técnica, reconhecendo uma gênese concretizante, cuja ocorrência é o próprio ato da invenção. É aí, no seu existir concreto, que cada objeto técnico deve ser abordado teoricamente, sem perder de vista que nele também estão guardadas as informaçôes psicológicas a respeito de sua invenção, ou mesmo de seu inventor e do conhecimento, capacidade e necessidade do grupo ao qual ele pertence, características essas que explicam sua existência ontológico-tecnológica. Eis a utilidade de uma mecanologia.

De acordo com Chabot (2003, p. 232), o adjetivo "concreto" é a novidade da tese de Simondon sobre o modo próprio de existência dos objetos técnicos. Na teoria da invenção, o autor distingue três etapas: a ideia do objeto na mente do inventor, a materialização dessa ideia e, finalmente, a concretização (fase na qual o inventor elimina as incompatibilidades do objeto técnico abstrato - detectadas na segunda fase, quando a ideia, por demais intelectual, se torna tecnicamente inviável). Esta última fase é caracterizada por uma tentativa de simplificação do objeto,

múltiplas perspectivas de análise de qualquer objeto. Referindo-se à sua origem latina (transducere traducere), acentuam-se no âmbito científico as ideias de traduzir e de transportar, ou seja, de converter (uma informação em sinal), enquanto Simondon se aproveita do termo, no sentido de produzir ou induzir a gênese de algo novo. 
carregando cada estrutura de uma pluralidade de funçóes; não somente as funções antigas são conservadas e melhor realizadas, mas a concretização traz propriedades novas, funçôes complementares que não tinham sido encontradas e que poderiam ser nomeadas 'funções superabundantes', constituindo a classe de um verdadeiro advento de possibilidades que se juntam às propriedades esperadas do objeto. $\left(\mathrm{CII}^{8}, 1197\right)$.

Através da invenção, portanto, um objeto é ampliado em suas propriedades. É justamente nisso que reside a tarefa do inventor: realizar a superabundância, em termos de eficácia do objeto diante de um problema dado e mesmo diante de um problema sequer previsto. Isso significa que concretizar um objeto é abri-lo para essa pluralidade e fazê-lo encontrar um modo de funcionamento coerente, de acordo com suas próprias leis. Do ponto de vista do projeto filosófico de Simondon, isso significa "que a técnica não é um conjunto de ideias concretizadas, mas um conjunto de coisas concretas que tem suas próprias leis." (CHABOT, 2003, p. 234). Cada objeto não é resultado senão de um movimento tripartite: sua ideia, sua materialização e as condiçóes de sua concretização (que envolve uma rede de eventos socioeconômicos na qual ele está integrado).

Simondon destaca o fato de que "o objeto técnico progride por redistribuição interior das funçôes em unidades compatíveis, substituindo o acaso ou o antagonismo da repartiçáo primitiva", levando em conta "o grupo sinérgico de funçôes" que "constituem o verdadeiro subconjunto no objeto técnico." (MEOT, 41). Essa organização de subconjuntos passa a ser considerada "a essência da concretização do objeto técnico é a organização dos subconjuntos funcionais no funcionamento." (MEOT, 41). Simondon está falando sempre do objeto concreto no qual cada peça, a partir do sistema sobre o qual se exercem múltiplas forças, produz efeitos independentes da intenção de seu inventor, embora de acordo com um determinado conhecimento científico universal. Dessa forma, o autor presta atenção ao desenvolvimento evolutivo dos objetos técnicos, mormente aqueles que chamamos de máquinas, isto é, aqueles nos quais é possível identificar as etapas de sua aparição histórica, a qual vai desde a fabricação artesanal antiga às possibilidades industriais do século XVII em diante. Em outras palavras, cada objeto técnico carrega em si a história do desenvolvimento da técnica, por meio dos conhecimentos científicos de cada etapa histórica, ainda que não de forma linear. São esses conhe-

8 SIMONDON, G. Cours sur l'imagination et l'invention, de 1966. 
cimentos trazidos pela ciência que possibilitam o desenvolvimento deste - e não daquele - objeto, vindo a marcar de forma decisiva o ritmo do progresso técnico e do aperfeiçoamento dos próprios objetos. Embora seja necessário reconhecer que os objetos técnicos, como vimos acima, têm uma história própria (como natural) que os torna independentes do uso humano e dos desejos de conhecimento científico que tentam incorporá-los.

Desde esse ponto, Simondon se pergunta a respeito da possibilidade de remontar à origem absoluta do nascimento da verdade técnica. Através de vários exemplos que traduzem a história evolutiva da técnica, o autor identifica a fecundidade de um momento primitivo, fundado na não saturação do próprio objeto consigo mesmo, algo que, no limite, o abriria para uma possível posteridade, pela qual ocorreria o longo processo de individuação (individuation) ${ }^{9}$ dos seres técnicos, que, para Simondon, "é a condição do progresso técnico." (MEOT, 70). Tal individuação "é possível pela recorrência de causalidade num meio que o ser técnico criou em torno de si mesmo e que o condiciona na mesma medida em que é condicionado por ele." (MEOT, 70). Conforme o autor, é preciso considerar o indivíduo como um efeito da individuação e não apenas a sua causa, o que significa reconhecer aquela espécie de resíduo pré-individual supracitado. $\mathrm{O}$ conceito, assim, dá mais importância aos processos de surgimento dos indivíduos técnicos do que aos indivíduos em si mesmos. Trata-se de um olhar de conjunto que pretende reconhecer a mediação existente entre os objetos técnicos fabricados e os elementos naturais, no seio dos quais os objetos se constituem enquanto tais. Exemplos disso são o óleo e água, o vento ou calor, que são ocorrências centrais de um artefato técnico e lhe dão a condição de sua própria existência enquanto objeto inventado. E é assim, como inventado, que cada objeto técnico existe de uma vez por todas. Porém, é também desse estado inicial que ele se abre sempre diante de um novo horizonte, o qual passa a formar a história evolutiva da técnica como

\footnotetext{
9 O conceito de individuação, o qual vem sendo utilizado desde a Antiguidade, principalmente com Aristóteles, passando pelo debate medieval dos universais e chegando até Schopenhauer, Nietzsche e Jung, está ligado ao "processo de realização de uma ideia, ou ainda o processo pelo qual um indivíduo se torna aquilo que ele é." (CHABOT, 2003, p. 231). Ao ler Aristóteles, que entende a individuação como um processo de encontro entre forma matéria, Simondon recusa tal perspectiva, para afirmar o indivíduo, não como "materialização de uma essência", nem como uma "substância estável" ou uma "matéria disforme", mas como "produto de uma relação" entre energia e estrutura. O indivíduo, para o filósofo, é aquele que faz brotar um mundo através da imaginação, um conceito que passa a ocupar um lugar especial na filosofia da individuação, que culmina na concretização técnica dos objetos inventados pelo homem. Sobre o tema da individuação na obra de Simondon, além de Chabot (2003), ver ainda Guchet (2005). Sobre a relaçấo de Simondon com Merleau-Ponty em torno dessa questão, ver o já citado artigo de Beistegui (2005).
} 
uma história sucessiva de gerenciamento dessas informaçóes existenciais originais, que se realizam no ato de sua própria invenção.

É no ato de inventar ${ }^{10}$ que residiria, justamente, a essência da técnica, porque ela permanece estável ao longo de um processo evolutivo no sentido, por exemplo, de que "o motor a gás é o ancestral do motor a gasolina e do motor a Diesel." (MEOT, 30). Inventar, do ponto de vista técnico, é resolver um problema, por meio de determinada inteligência, um problema que se encontra no mundo e que convoca o inventor, interpondo-se entre ele e o mundo. Ora, justamente por seu caráter de inventado, é possível falar de evolução temporal de todo objeto técnico e, com ele, contar a história genética da própria técnica em sua tecnicidade. $\mathrm{O}$ estudo da história dos objetos, portanto, não pode deixar de lado nem o meio geográfico e técnico - que Simondon chama de "meio associado" (MEOT, 55) ${ }^{11}$-, nem a economia de sua gênese própria, quer dizer, sua evolução enquanto determinada por seu ser técnico próprio, antes de qualquer determinação histórica, social ou econômica extrínseca. A questão central é que o objeto deve ser estudado como algo autorregulado associado ao meio ao qual ele está adaptado, ainda que, no caso das máquinas (ou seja, dos objetos técnicos mais complexos e aperfeiçoados) seja necessário reconhecer sua coerência interna, a autocorrelação das partes que formam seus esquemas de funcionamento. O objeto, nesse caso, é um misto de realidade humana e realidade natural. É por isso que o ato criador é igualmente um ato imaginativo, mas somente na medida em que tal imaginação antecipa uma resposta a determinado problema real, na forma de uma espécie de simulaçáo sugerida pelo meio e pelo estado presente de um objeto técnico. Mais uma vez, é preciso acentuar que a invenção não é um ato ex nihilo, como bem salientou Merleau-Ponty, ao comentar a obra de Simondon, numa de suas notas inéditas: "A constituição de uma tradição, de uma memória, de um passado, de uma história, de uma ordem de 'coisas', não ocorre como criação ex nihilo";

10 "Inventar", para Simondon, é uma ação que reúne os polos objetivos e subjetivos e, por isso, se diferencia tanto da ideia de descoberta quanto de criatividade, já que essas duas estariam ligadas unicamente ao polo da subjetividade. Se a descoberta, por isso, é um ato de novidade desligada de qualquer condição objetiva, a invenção parte de condiçóes objetivas e é fruto de uma tensão com a subjetividade produtora. É por isso que a filosofia da técnica, proposta por Simondon, integra ao mesmo tempo uma psicologia e uma tecnologia.

${ }^{11}$ Nesse sentido, inventar um objeto é também inventá-lo a partir de um meio já dado e, ao mesmo tempo, inventar o próprio meio no qual ele está inserido. Dessa maneira, uma locomotiva e os trilhos sobre os quais ela desliza formam um "conjunto técnico". Inventar um é também inventar outro. Inventar é intervir ontologicamente no mundo, alterando as estruturas da realidade, de acordo com as possibilidades guardadas nessa mesma realidade. 
"ex nibilo, ela é modulação" pois "a liberdade é sempre gestão de uma herança.” (MERLEAU-PONTY, 2005, p. 39). Inventar do nada é só uma ilusão, portanto, primeiro, porque todo inventor carrega consigo seu meio e porque, consequentemente, todo inventado está condicionado e condiciona tal ambiente. Caberia à filosofia gerenciar essa herança que é trazida originariamente por cada objeto técnico. Eis porque a história da técnica não é uma regressão a um passado original, mas um retorno genealógico que pretende compreender o que é agora levando em conta, o legado evolutivo que começou no ato inventivo e se estende na evolução. Tal tarefa é denominada por Simondon como história genética.

No ato de sua invenção, o objeto técnico surge no mundo como uma espécie de intermediação entre o objeto natural e a representação científica. Para isso, é preciso diferenciar o objeto técnico abstrato e o objeto técnico concreto: o primeiro "é a tradução material de um conjunto de noções e princípios científicos profundamente separados uns dos outros e vinculados apenas pelas suas consequências convergentes para a produção de um efeito buscado.” (MEOT, 46). Ao contrário, o segundo "aproxima-se do modo de existência dos objetos naturais, tende para coerência interna" e se apresenta como um "sistema de causas e efeitos que ocorrem circularmente no seu interior", fazendo com que ele perca a sua artificialidade, definida como a necessidade de que o homem intervenha para que tal objeto se mantenha na existência. Abstrato é o objeto retirado de seu meio. Concreto é aquele entendido a partir das relaçôes com esse meio. Artificial, portanto, não é aquilo que tenha sido criado pelo homem, mas justamente aquilo que depende de um vínculo estreito em relação ao homem para existir, ou seja, aquilo que depende da "ação superficializante do homem." (MEOT, 47). Fora disso, ele se torna mais concreto quanto mais independente do homem estiver. Um aviáo, nesse caso, é mais concreto do que um automóvel, porque está menos suscetível às interferências humanas, "a fim de aumentar a segurança de seu funcionamento e de diminuir o seu peso morto.” (MEOT, 30). Por razóes econômicas, o objeto técnico, como o avião, tende a ser construído para evitar a sua autodestruição e para se manter funcionando de maneira estável pelo maior tempo possível. Muitas vezes, a evoluçáo dos objetos técnicos ocorre pelas experiências de uso ou pela melhor adaptação de determinados materiais ou aplicação de novidades derivadas de pesquisas recentes. Estas são razōes de cunho técnico, enquanto motivaçóes e preferências difusas criadas pela propaganda, por exemplo, se apoiariam em questóes meramente sociais, com menos valor, portanto. 
Para o filósofo, é preciso reconhecer que cada objeto é resultado de um processo que se dá "ao final de uma série convergente" (MEOT, 26), a qual vai do abstrato ao concreto e "tende para um estado que faria do ser técnico um sistema inteiramente coerente consigo mesmo, inteiramente unificado.” (MEOT, 26). Falar de condições intrínsecas e perguntar sobre o ser próprio desses objetos, contudo, não é negar os fatores externos que influenciam a sua produção e funcionamento: "Simondon admite que as causas técnicas da evolução se combinam com causas econômicas, e estas últimas, por sua vez, se misturam a motivaçôes sociais (o gosto pelo luxo, $v$. g.)" ainda que as chamadas "causas técnicas" predominem sobre as demais (CUPANI, 2013, p. 61) - e é nesse caso que o progresso técnico ocorre com mais facilidade e eficácia. ${ }^{12} \mathrm{Na}$ verdade, conforme o autor, a evolução do modo de produção técnica, que vai da artesanal até a industrial, não é automática, restando conveniente pesquisar as suas causas, as quais residiriam na "imperfeição do objeto técnico abstrato" (MEOT, 29), que, sendo analítico, emprega mais matéria e mais trabalho de produçáo e, apesar de parecer "logicamente mais simples", é "tecnicamente mais complicado" - na medida em que nele ocorrem mais vínculos com a ação humana.

\section{O REGIME DA EVOLUÇÃo}

Como vimos até agora, a análise da natureza das realidades técnicas não existe sem, pelo menos, ter um desses três modos que explicam a sua história: [1] fornece uma relação determinada do vir-a-ser das realidades técnicas bem mais precisa do que todas as outras causas, [2] lança luz sobre todas as realidades técnicas possíveis, consideradas como um todo homogêneo e solidário, uma rede de relaçóes entre elementos individuais e conjuntos; [3] a temporalidade que vem do ritmo de relaxation permite caracterizar o tempo técnico próprio e, além disso, "que esse tempo de relaxation pode se tornar dominante em relação a todos os outros aspectos do tempo histórico, de modo que ele pode sincronizar os outros ritmos de desenvolvimento e parece determinar

\footnotetext{
${ }^{12} \mathrm{O}$ exemplo disso seria o automóvel, cuja fabricaçăo e modelagem é marcada muito mais por detalhes que o tornam socialmente desejável do que por questôes de cunho técnico: "O automóvel, objeto técnico cheio de inferências psíquicas e sociais, não convém ao progresso técnico: os progressos do automóvel advêm de domínios próximos, como a aviação, a marinha, os caminhóes de transporte." (MEOT, 26). Trata-se de perguntar sobre os aspectos inessenciais (porque extrínsecos) e aqueles que fazem parte da natureza própria dos objetos técnicos: "Quanto mais o carro deve responder às exigências importantes do utilizador, mais seus caracteres essenciais são sobrecarregados com uma servidão exterior." (MEOT, 28). Tal caráter inessencial vai contra a essência do ser técnico.
} 
toda evolução histórica, embora ele sincronize e implique somente as fases." (MEOT, 67). A lei de relaxation é um conceito introduzido na segunda parte de Du mode d'existence des objets techniques, a fim de traduzir a possibilidade de condensar as relações das modalidades históricas do objeto (elemento, indivíduo, conjunto), na medida em que a máquina, assim como é a vida, recusa a desordem e busca o equilíbrio de seu próprio sistema. Para Simondon, "o verdadeiro progresso dos objetos técnicos se efetiva através de um esquema de relaxation e não de continuidade; há conservação da tecnicidade como informação através dos ciclos sucessivos de evolução." (MEOT, 265).

A invenção técnica, como solução efetiva de um problema que deve ser representado objetivamente, permite pensar que a evolução genética é uma essência da realidade técnica, mas também que tal evolução deve ser pensada como variação significativa do ritmo do progresso técnico. Tais variaçôes, aliás, não devem ser tomadas apenas do ponto de vista dos graus, mas sobretudo da sua natureza própria. Além disso, as variaçôes devem ser distintas conceitualmente como maiores e menores, na forma de mudanças quase insensíveis e de novidades que parecem formar uma verdadeira ruptura na evolução.

A filosofia de Simondon, assim, funda um conhecimento genético da realidade técnica sobre a evolução propriamente técnica, acessando, como resultado, a própria dimensão histórico-genealógica dessa realidade em sua essência, ou seja, em sua tecnicidade. Nessa estratégia, o autor reconhece que não existe somente um modo de existência dos objetos técnicos, mas que há vários objetos técnicos, em diferentes modos de existência. A filosofia, ao afirmar a gênese da realidade técnica, alcança o fundamento ontológico da sua história, examinando a causalidade propriamente técnica dos objetos, em sua evolução e compreendendo sua lógica interna, isto é, que entre os diversos modos de existência existe uma passagem de causalidade, que vai dos conjuntos aos individuais e vice-versa. Assim, cabe reconhecer que "há uma solidariedade histórica entre as realidades técnicas", a qual passa pela afirmação desses elementos: "A solidariedade dos seres técnicos uns em relação aos outros no presente, mascara em geral esta outra solidariedade muito mais essencial, que exige uma dimensão temporal de evolução.” (MEOT, 40). A história genética dos objetos técnicos repousa, como vimos até aqui, na natureza própria desses objetos e sua causalidade própria, revelada a partir da sua condição de seres inventados, ou seja, de artefatos.

Nesse sentido, Simondon rompe com a noção de quadro sincrônico sucessivo da história da técnica, como é comum entre os historiadores, pois, 
para ele, interessam as linhas diacrônicas de mudanças e não apenas a tradicional relação de causalidade: o que muitas vezes desestimula uma visão de tal forma não sincrônica e não sucessiva da história técnica é justamente a ideia de causalidade, isto é, de algo que precede de algo e algo que causa algo. No caso dos objetos técnicos, essa causalidade não é fácil de ser demostrada, com o custo de que a sua história não venha à tona claramente. Os fatores de singularização dos objetos técnicos, portanto, passam por uma compreensão dessa diacronia de sua gênese, algo que comprova também a própria diversidade dos modos de existência desses mesmos objetos. Não há uma causalidade retilínea, mas justamente uma forma de ocorrência que o autor chama de "dents de scie" (MEOT, 66). Todavia, no geral, a genealogia dos objetos é compreendida de forma circular, pela "loi de relaxation". Nessa perspectiva, a história genética aparece como alternativa a uma história classificatória, a qual tentaria ordenar a totalidade dos objetos na lógica do discurso de espécies e gêneros, por exemplo. Tal discurso tenderia a isolar o objeto técnico, enquanto Simondon insiste na reticularidade, ou seja, na integração de cada objeto ao conjunto técnico, no seu aspecto de rede, no seu pertencimento a estruturas reticulares. Nessa medida, o objeto técnico não é mais somente uma ferramenta; e o hilemorfismo que separa matéria e forma, sujeito e objeto, é superado por uma tentativa de representar a própria ação inventiva ou a "rede de açôes em um sistema metastável." (REBER, 2008, p. 116). O ato, nessa medida, não é nem matéria e nem forma, é a relação que faz do ser um deveniente em processo de devir.

Assim, a questão da invenção como origem da história da técnica apresenta-se como estratégia de análise da evolução da realidade técnica, na sua dimensão histórica, que segue, na visão de Simondon, um traçado plural, não linear, nem simplesmente cronológico, uma história que procede a partir de pontos de vista ou problemas determinados, sem que se chegue à constituiçáo de uma realidade histórica total ou, ainda, a uma visão guiada pelo princípio dos paradigmas. Na Conferência de 1971, supracitada, por exemplo, o autor nega esse caráter totalizante para a Revolução Industrial: nem ela teria começado num mesmo momento, nem sequer teria alcançado todos os lugares com as mesmas características, muito menos nascido de uma vez por todas, como geralmente os livros de história parecem tentar nos convencer. Mesmo a ideia de que a ciência fecundou a técnica, de sorte a dar início ao movimento tecnológico da era moderna, é analisada, nesse texto, como algo muito global e generalista. Tal posição se apoia, segundo Chateau, numa concepção própria de filosofia: "A filosofia de Simondon não é uma ontologia da substância, é uma ontologia da relação e da gênese.” (CHATEAU, 2005, p. 47). 
Nessa esteira, outras questóes aparecem, entre as quais está a pergunta sobre a perfeição técnica. Permeados por uma confusão entre automatismo (próprio da máquina) e a perfeição, nos seus diferentes graus, os arautos da técnica acabam favorecendo muitas ilusôes a respeito do poder da técnica, esquecendo que o automatismo (e sua forma industrial, a automação) é o degrau mais baixo, ainda bem distante do pretendido requinte de uma máquina perfeita. De acordo com o autor, "a perfeição técnica é uma qualidade prática ou pelo menos, o suporte material e estrutural de certas qualidades práticas”; dessa forma, "uma boa ferramenta não é somente aquela que é bem-feita e bem talhada" (MEOT, 89), mas aquela cujo esquema de funcionamento e o modo como ela recolhe em si o resultado do funcionamento de um conjunto técnico são realizados de forma exata. Por isso, para Simondon, "a tecnicidade do objeto é mais que uma qualidade de uso; ela é aquilo que, nele, ajunta-se a uma primeira determinação dada por uma relação de forma e de matéria; ela é uma espécie de intermediário entre forma e matéria" (MEOT, 89), um "degrau de concretização do objeto". A perfeição do objeto pode revelar características tâo complexas quanto aquelas relacionadas ao ambiente cultural de um povo ou de uma nação. Cada objeto técnico guarda, desde sua origem, "um julgamento de valor intrínseco." (MEOT, 91). A tecnicidade, por isso, é um estado de combinação do nível individual de existência técnica e dos conjuntos de elementos nos quais ele está inserido.

Outra questão tem a ver com a abertura ou a sensibilidade do objeto. Simondon destaca a importância da "margem de indeterminaçáo" que torna a máquina de alta tecnicidade suscetível à informação, quer dizer, portadora de certa "sensibilidade" para a informação. É justamente por sua abertura, porque náo é um sistema autônomo fechado, que a máquina pode ser organizada desde fora, ou seja, pode acolher a açáo do homem como "organizador permanente" e como "intérprete vivo das máquinas umas em relação às outras." (MEOT, 12). O conceito de informação torna-se central no projeto que pretende recusar a ideia do ser como imóvel quanto aquela que o afirma como simplesmente entregue ao próprio devir: "esses dois obstáculos são superados graças à noção de informação idêntica à ressonância interna do sistema em vias de individuação." (REBER, 2008, p. 119). A informação seria, nesse caso, não apenas um dado interior, mas também exterior, isto é, ela se apresentaria como uma mediação entre os subconjuntos técnicos, recusando qualquer visão que afirmasse uma pura substancialidade do ser em contraposição aos demais. Tal visão seria definitivamente insuficiente para pensar a realidade própria dos 
objetos técnicos. Restituindo a tais objetos a sua sucessão de equilíbrios metastáveis, Simondon torna possível a sua história genética.

\section{CONSIDERAÇÓES FINAIS}

Restaria perguntar qual homem está preparado para uma tal tarefa, ou seja, considerar a máquina como parte de sua existência humana e cultural. Sem dúvida, só aquele que toma consciência da realidade própria da máquina e dos demais objetos técnicos, aquele que se abstém de sua relação cotidiana de uso, isto é, não o próprio homem técnico que estaria, por assim dizer, tecnificado. Em outras palavras, se "a máquina tomou o lugar do homem é porque este assume uma função de máquina” (MEOT, 17) - é isso que precisa ser corrigido. Tal tarefa caberia a um engenheiro de organização, "que seria como o sociólogo e o psicólogo das máquinas, vivendo no meio desta sociedade de seres técnicos dos quais ele é a consciência responsável e inventiva.” (MEOT, 14). Como psicólogo da máquina, o homem deixaria de perguntar apenas por sua realidade exterior, ou seja, por suas condiçôes de usabilidade (pergunta, aliás, típica dos cientistas), e faria a pergunta mesma sobre o modo de existência dessas peças instrumentais. Caberia a ele conhecer os "esquemas de funcionamento contidos nos objetos técnicos." (MEOT, 14). Ao lado desse sociólogo ou psicólogo, devem coexistir, segundo Simondon, o tecnólogo ou mesmo um mecanólogo, a fim de que tais esquemas de funcionamento sejam desvendados, compreendidos e ensinados, "como são ensinados os fundamentos da cultura literária." (MEOT, 15).

Haveria, por isso mesmo, uma necessidade de iniciação à técnica, nos moldes do que ocorre com a própria ciência, a arte ou a física teórica. A isso Simondon chama de "reforma da cultura": aproximar o homem da máquina, não em sentido externo, mas em sentido próprio, dando-se conta de que há tanto uma natureza própria das máquinas a ser desvendada quanto uma soma infinita de relaçóes entre elas e delas com o próprio homem, nas quais estáo implicados valores e motivaçóes próprios daquilo que chamamos, no geral, de cultura. Só assim a máquina seria analisada em função de sua relação com a cultura, algo que, no limite, levaria ao rompimento da mera apropriação vazia de esquemas, símbolos, qualidades e analogias fornecidos pela máquina, a fim de assumir-se conscientemente em suas bases de apropriaçôes e significaçôes, evitando tantas distorçôes vigentes. Para isso é preciso corrigir as falhas na informação, o que significa compreender os homens e as máquinas como partícipes de uma existência simultânea. O resultado seria a conquista de uma ação, a qual, por combater a alienação principal da 
nossa cultura, acaba por efetivar-se como ação política e social: "Ela pode dar ao homem os meios para pensar sua existência e sua situação em função da realidade que o circunda." (MEOT, 16). Como filosofia, tal tarefa assume uma atitude crítica diante dos mitos e dos estereótipos que têm marcado a relação do homem com a cultura.

FALABRETTI, E. S.; OLIVEIRA, J. R. "Management of an inheritance": the genetic history of technical objects in the philosophy of Gilbert Simondon. Trans/formlação, Marília, v. 41, n. 2, p. 177-196, Abr./Jun., 2018.

ABSTRACT: The aim of this article is to analyze the concept of genetic history in the thought of the French philosopher Gilbert Simondon. To do this it is necessary to consider a philosophy that intends to break the barriers that separate technology and culture, and from there proceeds to analyze the mode of existence of technical objects. From this perspective, the technicity of technology is analyzed, using the concept of invention in order to formulate a genetic history of technology that gathers both subjective (psychological) and objective (technological) elements, according to the transductive method. A project that, in the end, is presented as "management of an inheritance", in the words of Merleau-Ponty.

KeYwords: Simondon. Technique. Genetics. Invention. Evolution.

\section{REFERÊNCIAS}

BEISTEGUI, M. Réduction et transduction: de Merleau-Ponty à Simondon. In: Chiasmi International. Publication Trilingue autor de la pensée de Merleau-Ponty, n. 7; Milão: Mimesis; Paris: Vrin; Memphis: University of Memphis, 2005. p. 127-151.

CHABOT, P. La philosophie des techniques de Simondon. In: ; HOTTOIS, G. (Éd.). Les philosophes et la technique. Paris: Vrin, 2003. p. 231-242.

CUPANI, A. Filosofia da tecnologia: um convite. 2. ed. Florianópolis: Ed. da UFSC, 2013.

DOMINGUES, I. Simondon, a cibernética e a mecanologia. Scientia Studia, v. 13, n. 2, p. 283-306, abr.-jun. 2015.

GOUCHET, X. Simondon, la cybernétique et les sciences humaine. In: Chiasmi International. Publication Trilingue autor de la pensée de Merleau-Ponty, n. 7; Milão: Mimesis; Paris: Vrin; Memphis: University of Memphis, 2005. p. 187-205. 
MERLEAU-PONTY, M. Notes de travail inédites. Biblioteque Nationale de France, v. VIII. In: Chiasmi International. Publication Trilingue autor de la pensée de MerleauPonty, n. 7; Milão: Mimesis; Paris: Vrin; Memphis: University of Memphis, 2005. p. 39.

REBER, B. Quand la nouveauté technique oblige à penser autrement. Hans Jonas, John Dewey, Gilbert Simondon. In: SCHMIT, P.-É.; CHARDE, P.-A. (Dir.). Phénoménologie et technique(s). Paris: Le Cercle Herméneutique, 2008. p. 105-126. (Collection Phéno, Série Philosophie Générale).

SIMONDON, G. Cours sur l'imagination et l'invention. Bulletin de Psychologie, 1966. . L'individu et sa genese physic-biologique. Paris: Presses Universitaire de France, 1989.

L'Linvention dans les techniques. Cours et conférences. Édition établie et présentée par Jean-Yves Chateau. Paris: Éditions du Seuil, 2005.

. Du mode d'existence des objets techniques. Nouvelle édition revue et corrigée.

Paris: Aubier, 2012.

Recebido: $17 / 08 / 2015$

Aprovado: 23/01/2017 